\title{
ВMJ Global Health Estimating the incidence of abortion: using the Abortion Incidence Complications Methodology in Ghana, 2017
}

\author{
Chelsea B Polis (D , , ${ }^{1,2}$ Philicia W Castillo, ${ }^{1}$ Easmon Otupiri, ${ }^{3}$ Sarah C Keogh, ${ }^{1}$ \\ Rubina Hussain, ${ }^{1}$ Emmanuel K. Nakua, ${ }^{4}$ Roderick Larsen-Reindorf, ${ }^{5}$ \\ Suzanne O Bell ${ }^{6}$
}

\begin{abstract}
To cite: Polis CB, Castillo PW, Otupiri $\mathrm{E}$, et al. Estimating the incidence of abortion: using the Abortion Incidence Complications Methodology in Ghana, 2017. BMJ Global Health 2020;5:e002130. doi:10.1136/ bmjgh-2019-002130
\end{abstract}

Handling editor Sanni Yaya

- Additional material is published online only. To view, please visit the journal online (http://dx.doi.org/10.1136/ bmjgh-2019-002130).

Received 30 0ctober 2019 Revised 20 February 2020 Accepted 28 February 2020

Check for updates

(c) Author(s) (or their employer(s)) 2020. Re-use permitted under CC BY-NC. No commercial re-use. See rights and permissions. Published by BMJ.

For numbered affiliations see end of article.

Correspondence to

Dr Chelsea B Polis;

cpolis@guttmacher.org

\section{ABSTRACT}

Introduction Induced abortion is legally permitted in Ghana under specific conditions, but access to services that meet guidelines approved by government is limited. As part of a larger project comparing five methodologies to estimate abortion incidence, we implemented an indirect estimation approach: the Abortion Incidence Complications Methodology (AICM), to understand the incidence of abortion in Ghana in 2017.

Methods We drew a nationally representative, twostage, stratified sample of health facilities. We used information from 539 responding facilities to estimate treated complications stemming from illegal induced abortions, and to estimate the number of legal abortions provided. We used information from 146 knowledgeable informants to generate zonal multipliers representing the inverse of the proportion of illegal induced abortions treated for complications in facilities in Ghana's three ecological zones. We applied multipliers to estimates of treated complications from illegal abortions, and added legal abortions to obtain an annual estimate of all induced abortions.

Results The AICM approach suggests that approximately 200000 abortions occurred in Ghana in 2017, corresponding to a national abortion rate of 26.8 (95\% Cl 21.7 to 31.9 ) per 1000 women 15-49. Abortion rates were lowest in the Northern zone (18.6) and highest in the Middle zone (30.4). Of all abortions, $71 \%$ were illegal. Conclusion Despite Ghana's relatively liberal abortion law and efforts to expand access to safe abortion services, illegal induced abortion appears common. A concurrently published paper compares the AICM-derived estimates presented in this paper to those from other methodological approaches.

\section{INTRODUCTION}

In Ghana, the conditions for legal abortion provision are relatively liberal compared with many other African countries. A 1985 amendment to the Criminal Code made abortion legal in cases of rape, incest, fetal abnormality or disease or 'defilement of a female

\section{Key questions}

What is already known?

- In Ghana, very few nationally representative estimates of the incidence of induced abortion exist, and to date, all have relied on self-reported information, which may underestimate true abortion incidence rates.

What are the new findings?

- Using the Abortion Incidence Complications Methodology (AICM), we report the first nationally representative study estimating the incidence of induced abortion (without relying on women's selfreported abortions) in Ghana, accounting for abortions obtained from registered medical providers in approved facilities and those procured outside of the formal healthcare system.

- The AICM approach estimated that approximately 200000 induced abortions occurred in Ghana in 2017 , equivalent to an abortion rate of $26.8(95 \% \mathrm{Cl}$ 21.7 to 31.9 ) abortions per 1000 women aged 1549; rates varied across the three ecological zones of Ghana.

- We estimate that a majority of abortions obtained in $2017(71 \%)$ were illegal.

idiot' or to protect physical or mental health. ${ }^{1}$ Official guidelines state that in addition to meeting these criteria, legal abortions must be performed by registered health personnel (physician, nurse or midwife) with relevant training and in an approved facility. ${ }^{12}$ To best reflect language currently used in Ghanaian law, hereafter we refer to abortions meeting all of these criteria as 'legal' and to abortions not meeting all of these criteria as 'illegal'. Abortion safety is a public health concern, and illegal abortions are disproportionately unsafe compared with legal abortions. ${ }^{3}$ In practice, women who procure abortions from unregistered providers and/or from 


\section{Key questions}

What do the new findings imply?

- Despite safe abortion services being legal in Ghana under specific circumstances for over 30 years, a majority of abortions obtained in Ghana in 2017 were illegal, and thus, potentially unsafe.

- These national and zonal estimates can enable stakeholders to assess progress towards reducing unsafe abortion and decreasing maternal mortality in Ghana, and highlight the importance of ensuring knowledge of and access to reproductive health services including contraception, safe abortion and postabortion care.

- A concurrently published paper compares the AICM-derived estimates presented in this paper to those from other estimation approaches; contributing to a significant methodological advance in the estimation of a stigmatised behaviour that is challenging to measure.

unapproved facilities may not be aware of the illegality of the service.

Over the last 25 years, the Ministry of Health (MOH) and Ghana Health Service (GHS) have made efforts to expand access to postabortion care (PAC) and safe abortion services to decrease the negative impacts of unsafe abortion and improve access to legal abortion services. ${ }^{2}$ For example, in 1996, the GHS enacted policy reforms permitting providers with midwifery skills to provide PAC, expanding PAC provision beyond registered physicians. ${ }^{2}$ In 2003, provision of abortion was included in Ghana's national reproductive health policy, and operational protocols for Comprehensive Abortion Care (CAC) were issued in 2006 and 2012. ${ }^{4}$ These documents specify which providers may perform specific CAC-related services at various levels of the health system. For example, providers with midwifery training may administer medication abortion for pregnancies under 9 weeks, and also at later gestations in higher-level facilities where doctors can supervise. ${ }^{245}$ Between 2006 and 2016, the $\mathrm{MOH}$, GHS and other organisations launched programmes to improve CAC provision in a few regions. ${ }^{67}$

Despite these substantial efforts to incorporate safe abortion into policy, trainings and guidelines-clandestine, illegal and thus potentially unsafe abortions continue to occur. Complications from unsafe abortions contribute substantially to maternal morbidity and mortality. ${ }^{28}$ The maternal mortality ratio (MMR) in Ghana remains high, estimated at 310 maternal deaths per 100000 live births in 2017. ${ }^{9}$ This is lower than the 2015 MMR estimate for sub-Saharan Africa (546), but higher than that of all developing regions (239), and much higher than the MMR in developed regions (12). ${ }^{10}$ Abortion stigma and low knowledge of the abortion law among the Ghanaian public ${ }^{511}$ and medical professionals, ${ }^{712}$ coupled with misperceptions about the safety of legal abortion and inadequate access to safe abortion services, ${ }^{512}$ impede utilisation of CAC services. For example, among women who know what an abortion is, only $11 \%$ know it is legal under certain circumstances in Ghana, and only $25 \%$ believe they could obtain one if needed ${ }^{9}$ In addition, studies in Ghana have documented that some providers invoke 'conscientious objection' and refuse to provide safe and legal abortions in their facilities. $^{713}$ Furthermore, Ghana's National Health Insurance Scheme does not cover the cost of legal abortion, ${ }^{14}$ making it inaccessible to many. For these reasons, women often resort to unsafe and clandestine abortions outside of the health system, leaving them at increased risk for abortion-related morbidity and mortality.

In Ghana, regimens using mifepristone and misoprostol, or misoprostol alone, are permitted for medication abortion in the first and second trimesters. The proportion of abortions induced via medication abortion (both legally and illegally) appears to have increased in recent years, which has implications for abortion safety. Among all women who reported having an abortion in a nationally representative survey, the proportion who said they used pills to terminate their pregnancy increased from $16 \%$ in 2007 to $38 \%$ in $2017 .^{9}$ While registered providers in approved health facilities can provide medication abortions legally, people may also purchase medication abortion drugs from non-approved sources to self-induce an abortion, potentially due to lower costs or a desire to avoid being seen leaving an abortion-providing facility. ${ }^{15}$ While some women who self-induce using pills may receive incorrect drugs or dosages or have inadequate information about recommended regimens, ${ }^{16}$ global evidence suggests that overall, use of medication abortion drugs from the informal sector is associated with reductions in abortion-related complications. ${ }^{17-19}$

In Ghana, very few nationally representative estimates of abortion incidence exist. The 2017 Ghana Maternal Health Survey (GMHS) found that $6.7 \%$ of women aged 15-49 reported having had an abortion in the 5 years preceding the survey; roughly equivalent to 13.4 abortions per 1000 women per year (assuming abortion rates remained constant over those 5 years and not accounting for multiple abortions to the same person). However, such self-reports are subject to under-reporting. ${ }^{20}{ }^{21} \mathrm{~A}$ community-based survey done in 1997-1998 in southern Ghana estimated an induced abortion rate of 17 per 1000 women aged 15-49, but was not nationally representative. ${ }^{22}$ A 2008-2011 community-based survey conducted in the Brong Ahafo region reported figures roughly equivalent to 9.5 abortions per 1000 women 15-49 annually. ${ }^{23}$ A Bayesian hierarchical model produced a subregional estimate for induced abortion in West Africa of 31 per 1000 women aged 15-44 for 2010-14 (equivalent to approximately 28 for women aged 15-49), but was not specific to Ghana. ${ }^{2425}$ More recent and accurate estimates of national and subnational abortion rates, and information on the extent to which women continue to resort to procuring abortion from illegal sources, would better equip stakeholders to assess progress towards reducing unsafe abortion and ensuring adequate access to contraceptive, abortion and PAC services.

To address this evidence gap, we conducted a largescale study ${ }^{26}$ in Ghana to estimate abortion incidences 
nationally and for each of the three ecological zones. The study tested multiple methodologies, this article presents results from the Abortion Incidence Complications Methodology (AICM). The standard AICM has been used in over 20 countries, including 11 in Africa, and can be applied (with methodological adaptations) to contexts such as Ghana where abortion is legally available for certain indications, but often performed illegally by untrained or unapproved providers. ${ }^{27} 28$ Additional objectives included estimating the proportion of abortions performed illegally and the rates of treatment in facilities for complications of induced abortion.

\section{METHODS}

\section{Overview}

The AICM relies primarily on two surveys: a Health Facilities Survey (HFS) of a nationally representative sample of facilities with the potential to provide PAC and/or abortion, and a Knowledgeable Informants Survey (KIS), among a purposive sample of individuals knowledgeable about abortion in the country.

Women undergoing abortion experience one of three outcomes: no complication, a complication that does not receive treatment in a facility, or a complication that receives treatment in a facility. As detailed below, we use HFS data to estimate the latter: the number of postabortion complications (whether from legal or illegal induced abortions or from miscarriages) treated in health facilities annually. We adjust this to isolate the number of treated complications stemming from illegal induced abortions. Next, we use KIS data to estimate a multiplier: the inverse of the percent of all illegal induced abortions that result in a complication that receives treatment. The multiplier serves to inflate the adjusted PAC cases to account for women who had illegal abortions for which treatment in a facility was either not obtained or not required. Applying the multiplier to the adjusted PAC caseloads yields an estimate of all induced, illegal abortions annually. Adding the annual number of legal abortions (collected in the HFS) produces an annual estimate of all (legal and illegal) abortions.

Data collection occurred between June and October 2018. We trained study staff and pilot-tested questionnaires prior to initiating fieldwork. After undergoing informed consent, respondents completed a face-toface interview conducted by interviewers using a standardised questionnaire on an Open Data Kit-enabled electronic device. We did not offer incentives for interview participation.

Informed consents and questionnaires were in English, as we anticipated the majority of our respondents spoke English. We ensured that interviewers travelling to various regions spoke local languages to accommodate respondents who requested interviews in a non-English language. During training, staff discussed translations for key terms in multiple languages.

\section{Patient and public involvement}

We did not directly involve identified abortion patients in study planning, but we sought guidance for study planning and results dissemination from our Technical Advisory Committee, which included community representatives and technical experts.

\section{HFS sampling and fieldwork}

From the Central Health Information Management System of the GHS, we obtained a list of all health facilities that reported data through the District Health Information Management System in 2017. Our sampling universe included all facility types in which PAC and/or abortion may be offered, with the exception of community-based health planning and services (CHPS) facilities (which very rarely offer PAC/abortion services ${ }^{29}$ and nongovernmental organisations (NGOs) $(n=21)$, whose caseload data we obtained directly. Our final sampling frame contained 2758 facilities in all 216 districts.

We constructed a stratified two-stage sampling design with four strata to generate a nationally representative sample of health facilities. One stratum included all teaching and regional hospitals, sampled with certainty. The other three strata consisted of all remaining facility levels combined (district/university hospitals or polyclinics, other hospitals, health centres and midwife/ maternity homes) in each of Ghana's three ecological zones (Northern zone: Upper West, Upper East and Northern regions; Middle zone: Brong-Ahafo, Ashanti, Eastern and Volta regions; and Coastal zone: Western, Central and Greater Accra regions). Among these three strata, we conducted a two-stage stratified cluster sampling design, first selecting 121 of the 216 districts in the country with probabilities proportionate to-size, then selecting facilities within sampled districts with probabilities inversely proportionate to size. We selected facilities in the Northern zone at twice the rate of facilities in the Middle and Coastal zones to enable computation of representative estimates for each zone. We calculated weights as non-response-adjusted inverses of known selection probabilities for each sample facility. In total, we sampled 608 non-NGO facilities, and in 539 facilities, we completed an interview with a senior personnel member knowledgeable about PAC and, where relevant, abortion services at that facility. HFS interviews were conducted by 17 individuals (bachelors, masters or PhD students), each with several years' experience conducting interviews on sexual and reproductive health issues, all of whom were supervised by seven senior staff members. Final estimates are weighted; sample stratification and clustering are incorporated in CI estimation.

\section{KIS sampling and fieldwork}

Our in-country experts compiled a purposive list of senior and mid-level informants knowledgeable about the conditions under which women in Ghana obtain abortions, regardless of legality, safety or source, based throughout the country. Informants included clinician 
and non-clinician professionals (eg, doctors, nurses, midwives, programme managers, traditional leaders, community health workers, researchers, etc). We aimed to have adequate representation of informants across residence, sector and whether they were clinicians, since over-representation of one group's perspective may skew the responses. HFS participants were ineligible to participate in the KIS. KIS interviews were conducted by seven senior staff members with substantial experience conducting interviews on sexual and reproductive health issues, all of whom were supervised by the coprincipal investigator (EO).

We interviewed 146 KIS respondents (32 in Northern Zone, 56 in Middle and 58 in Coastal); no invited participants refused an interview. We dropped three respondents for non-response on key questions, and two for limited ( $<1$ year) experience in current profession. The analytical population averaged 44 years old with 12 years in current occupation. About $41 \%$ were doctors, nurses or midwives and $65 \%$ were female. The average number of years working in a rural area was 7 (range: 0-36, median: 8.35 ), and only $11 \%$ had $<1$ year working in a rural area. Approximately $61 \%$ worked in the public sector, $30 \%$ private, and $9 \%$ in NGO, faith based or other sector.

\section{Statistical analysis}

Detailed information on the analytic steps are provided in online supplementary appendix 1a. We preregistered the analysis plan on the Open Science Framework (https:// osf.io/285ew). We conducted analysis in Stata/MP V.15.

\section{Role of the funding source}

The sponsors of the study had no role in study design; collection, analysis or interpretation of the data; or in the writing or decision to submit the report. All authors had full access to all data and final responsibility for the decision to submit for publication.

\section{RESULTS}

\section{HFS service provision}

Out of 608 HFS facilities sampled, we completed interviews with $89 \%$ (539 facilities) (table 1). Among the 69 sampled facilities from which we did not obtain information, most $(n=54)$ were ineligible (ie, closed prior to 2017, could not be found, ineligible facility type, duplicate listing), while the rest $(\mathrm{n}=15)$ were eligible but had recently closed $(n=11)$ or had no staff available or willing to interview $(\mathrm{n}=4)$. Thus, among 554 eligible facilities, we had a $2.7 \%$ non-response rate.

Of the 539 facilities that completed interviews, 337 (63\%) offered PAC and 103 (19\%) reported providing abortion in the last year (table 1). An additional 18 facilities reported providing abortion, but had not provided any during the last 12 months. Provision of both PAC and abortion was nearly universal at teaching and regional hospitals (90\%-100\%). At district or university hospitals and polyclinics, as well as other hospitals, PAC provision remained high $(86 \%-93 \%)$, but abortion provision was substantially lower $(20 \%-52 \%)$. Between $41 \%$ and $61 \%$ of health centres, clinics and midwifery/maternity homes offered PAC, whereas only $8 \%-14 \%$ offered abortion.

Nationally, an estimated 69846 (95\% CI 54120 to 85 572) PAC cases stemming from miscarriages or induced abortions (legal or illegal) were treated at facilities in Ghana in 2017 (table 2). District hospitals handled over a third $(36.6 \%)$ of these, with other hospitals handling $22.6 \%$ and health centres handling $20.7 \%$. An estimated

Table 1 Facilities sampled, interviewed and providing PAC and/or abortion, Ghana Health Facilities Survey

\begin{tabular}{|c|c|c|c|c|c|c|}
\hline & $\begin{array}{l}\text { \# facilities } \\
\text { in universe } \\
\text { possibly } \\
\text { providing } \\
\text { PAC or } \\
\text { abortion }\end{array}$ & $\begin{array}{l}\#(\%) \text { facilities } \\
\text { sampled }^{*}\end{array}$ & $\begin{array}{l}\text { \# (\%) sampled } \\
\text { facilities } \\
\text { completing } \\
\text { interviews }^{*}\end{array}$ & $\begin{array}{l}\text { \# sampled } \\
\text { facilities } \\
\text { completing } \\
\text { interviews† }\end{array}$ & $\begin{array}{l}\text { \# (\%) of } \\
\text { interviewed } \\
\text { facilities } \\
\text { providing PAC† }\end{array}$ & $\begin{array}{l}\#(\%) \text { of } \\
\text { interviewed } \\
\text { facilities } \\
\text { providing } \\
\text { abortion in the } \\
\text { last yearf }\end{array}$ \\
\hline Teaching hospital & 4 & $4(100)$ & $4(100)$ & 4 & $4(100)$ & $4(100)$ \\
\hline Regional hospital & 10 & $10(100)$ & $10(100)$ & 10 & $10(100)$ & $9(90)$ \\
\hline $\begin{array}{l}\text { District/university hospital } \\
\text { or polyclinic }\end{array}$ & 184 & $47(26)$ & 47 (100) & 56 & $52(93)$ & $29(52)$ \\
\hline Other hospital & 378 & $85(22)$ & $75(88)$ & 66 & $57(86)$ & $13(20)$ \\
\hline Health centre & 923 & $208(23)$ & 203 (98) & 217 & $133(61)$ & $31(14)$ \\
\hline Clinic & 916 & $182(20)$ & $149(82)$ & 139 & $57(41)$ & $11(8)$ \\
\hline $\begin{array}{l}\text { Midwifery/maternity } \\
\text { homes }\end{array}$ & 343 & $72(21)$ & $51(71)$ & 47 & $24(51)$ & $6(13)$ \\
\hline Sampled total & 2758 & $608(22)$ & $539(89)$ & 539 & $337(63)$ & $103(19)$ \\
\hline NGO (caseload data only) & 21 & $21(100)$ & NA & NA & NA & NA \\
\hline
\end{tabular}

${ }^{*}$ Facility type as sampled.

†Facility type as reported

NA, not applicable; NGO, non-governmental organisations; PAC, postabortion care. 
Table 2 Weighted national PAC and abortion caseloads by facility type, Ghana Health Facilities Survey

\begin{tabular}{|c|c|c|c|c|c|c|}
\hline & \multicolumn{2}{|c|}{ Annual total PAC caseload* } & \multirow{2}{*}{$\begin{array}{l}\% \text { of PAC } \\
\text { caseload } \\
\text { by facility } \\
\text { type }\end{array}$} & \multicolumn{2}{|c|}{ Annual legal abortion caseload } & \multirow{2}{*}{$\begin{array}{l}\% \text { of legal } \\
\text { abortion } \\
\text { caseload } \\
\text { by facility } \\
\text { type }\end{array}$} \\
\hline & Estimate & $95 \% \mathrm{Cl}$ & & Estimate & $95 \% \mathrm{Cl}$ & \\
\hline Teaching hospital & 3435 & - & 4.9 & 1798 & - & 3.1 \\
\hline Regional hospital & 1483 & - & 2.1 & 2586 & - & 4.4 \\
\hline $\begin{array}{l}\text { District or university } \\
\text { hospital or polyclinic }\end{array}$ & 25588 & $\begin{array}{l}11095 \text { to } 40 \\
080\end{array}$ & 36.6 & 20351 & 11456 to 29246 & 34.9 \\
\hline Other hospital & 15764 & $\begin{array}{l}10176 \text { to } 21 \\
352\end{array}$ & 22.6 & 3346 & 629 to 6063 & 5.7 \\
\hline Health centre & 14492 & 8093 to 20891 & 20.7 & 8796 & 5411 to 12180 & 15.1 \\
\hline Clinic & 5822 & 3803 to 7841 & 8.3 & 5809 & 1053 to 10565 & 10.0 \\
\hline $\begin{array}{l}\text { Midwifery/maternity } \\
\text { homes }\end{array}$ & 2821 & 1283 to 4359 & 4.0 & 1066 & 56 to 2075 & 1.8 \\
\hline NGOs & 443 & - & 0.6 & 14492 & - & 24.9 \\
\hline TOTAL & 69846 & $\begin{array}{l}54120 \text { to } 85 \\
572\end{array}$ & & 58243 & 47502 to 68984 & \\
\hline
\end{tabular}

*Includes PAC cases stemming from spontaneous or induced (legal or illegal) abortion.

NGOs, non-governmental organisations; PAC, postabortion care.

58243 (95\% CI 47502 to 69 984) legal abortions were performed in health facilities in Ghana in 2017. Over onethird $(34.9 \%)$ were provided at district hospitals. NGOs and health centres provided the next largest proportions of legal abortions at $24.9 \%$ and $15.1 \%$, respectively.

After excluding referral visits, PAC cases due to late miscarriages and PAC cases stemming from legal abortions (which represent, respectively, 3\%, $85 \%$, and $12 \%$ of PAC cases removed), we estimated there were 38374 (95\% CI 28581 to 48 167) unique, illegal induced abortions that resulted in complications and received PAC in a health facility (table 3 ).

\section{Abortion incidence}

We estimated that 199559 (95\% CI 161495 to 237 622) induced abortions occurred in Ghana in 2017, translating to a rate of 26.8 (95\% CI 21.7 to 31.9$)$ abortions per 1000 women aged 15-49 (table 4 ). The abortion rate was lowest in the Northern Zone (18.6, 95\% CI 14.7 to 22.5), followed by the Coastal Zone $(25.2,95 \%$ CI 18.9 to 31.6) and the Middle Zone (30.4, 95\% CI 21.0 to 39.9$).$ We estimated the national abortion ratio to be $22.1(95 \%$ CI 17.9 to 26.3) per 100 live births in 2017; estimated as 11.8 (95\% CI 9.3 to 14.3$)$ in the Northern Zone, 22.7 (95\% CI 17.0 to 28.4 ) in the Coastal zone and 25.5 (95\% CI 17.6 to 33.4 ) in the Middle Zone.

Nationally, $70.8 \%$ of all abortions were illegal, corresponding to a count of 141316 (95\% CI 107719 to 174 913) illegal abortions, and estimated as $60.1 \%$ in the Coastal Zone, $72.2 \%$ in the Northern zone, and $78.3 \%$ in the Middle Zone. We estimated that $25.5 \%$ (results not shown) of women who had an illegal induced abortion in Ghana in 2017 received treatment for complications in a health facility.
Overall, we estimated that 5.7 per 1000 Ghanaian women aged 15-49 obtained treatment at a facility for complications resulting from an illegal or legal abortion (estimates reflect the likelihood of complications as well as access to facility-based care). The overall treated complications rates varied from 2.9 in the Northern Zone to 7.7 in the Middle zone. This variation derived primarily from variation in the zonal treated complication rates for illegal abortions (2.5 to 7.1), whereas treated complication rates for legal abortions were similar across zones (0.4-0.6).

\section{DISCUSSION}

The AICM estimated an overall abortion rate of 26.8 per 1000 women aged $15-49$. This is similar to the abortion rate of 28 reported for West Africa in a Bayesian hierarchical model, ${ }^{24}$ and substantially higher than the self-reported estimate of 13.4 from GMHS. ${ }^{9}$ Our Coastal Zone estimate (25.2) was also higher than that from a 1997-1998 survey in southern Ghana (17). ${ }^{22}$ In a concurrently published manuscript, we compare the AICM estimates presented in this paper to those from other estimation approaches. ${ }^{26}$

Despite Ghana's relatively liberal abortion law, and efforts to expand access to safe abortion services, we estimated that $71 \%$ of the nearly 200000 abortions in Ghana in 2017 were illegal. A recent study among Ghanaian women who self-reported an abortion in the last 5 years classified $64 \%$ of these abortions as unsafe (according to method, provider type and location). ${ }^{30}$ Our results suggest that women in the Middle zone were more likely to resolve a pregnancy via abortion (abortion ratio: 25.5), 


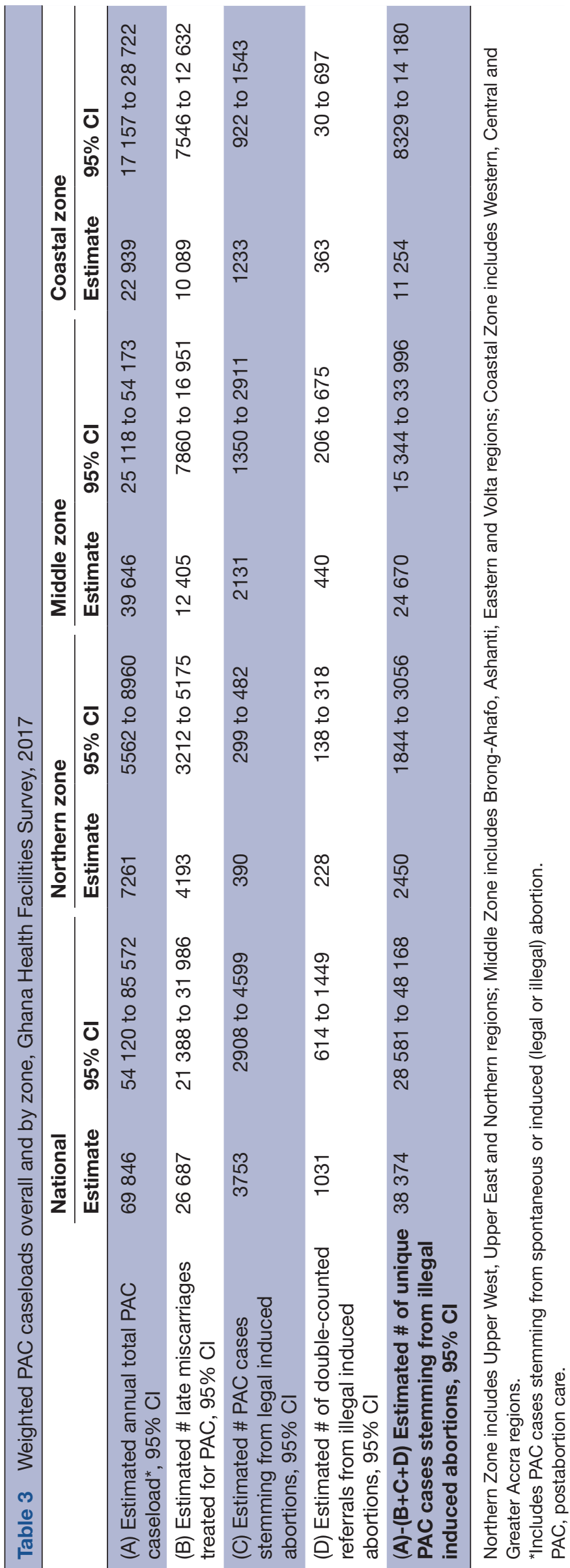

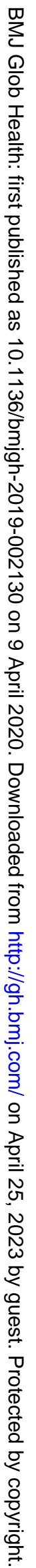




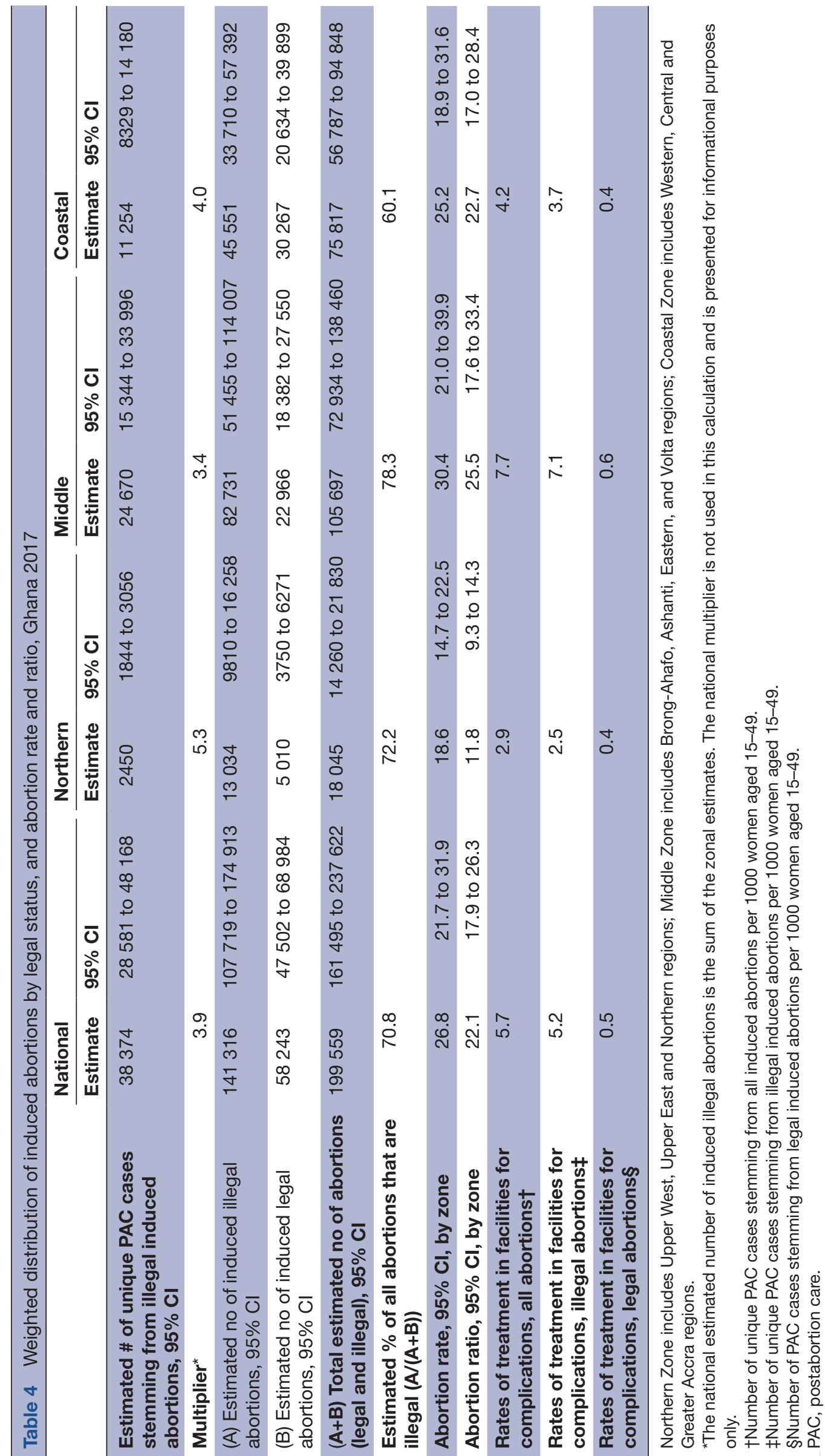

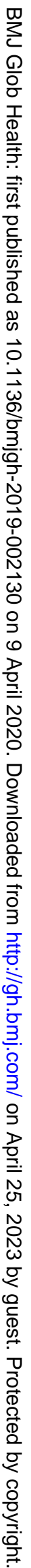


while women in the Northern zone were least likely (abortion ratio: 11.8).

This study has several strengths. We used an established methodology to estimate abortion incidence, which will enable us to compare these AICM-derived estimates to those from multiple alternative approaches. In conjunction, these findings represent a methodological advancement in the estimation of a stigmatised procedure that is challenging to measure. The AICM enables estimation of the proportion of induced abortions that are illegal. We collected nationally representative data from facilities, and among eligible facilities, had a low non-response rate $(2.7 \%)$. Our estimate for legal abortions was obtained directly from facilities; illegal abortion estimates require additional assumptions and adjustments. We preregistered our analysis on the Open Science Framework. This project helps fill an important knowledge gap on sexual and reproductive health indicators and needs, zonally and nationally, which can be useful to inform policy and programs in Ghana.

This study also has several limitations. Excluding CHPS facilities from our sampling universe may have resulted in minor caseload underestimates, since a very small number of CHPS facilities may provide these services. Our estimates are described as pertaining to 2017 because our data were collected during 2018 and some respondents (and all NGOs) provided caseloads pertaining to the prior year (2017). However, other facilities provided caseloads pertaining to the prior month (which would have been in 2018); we expect that estimates are unlikely to change noticeably between the 2 years. As detailed elsewhere,${ }^{27}$ the AICM is unable to provide information on characteristics of individual women seeking PAC or abortion, nor on the severity of abortion complications. Furthermore, the AICM provides approximate estimates (not exact measures), since multiple assumptions are required. For example, as described in online supplementary appendix $1 \mathrm{~b}$, adjustments to PAC caseloads (ie, removing complications stemming from miscarriage or legal abortion, or referral visits) require several assumptions, including that: (1) only later miscarriages require care in a health facility, (2) we identified an appropriate proxy for the proportion of late miscarriages receiving care and (3) HFS respondents could accurately estimate things like the proportion of PAC cases at their facility stemming from legal abortion, or the proportion of patients ultimately treated at the facility to which they were referred. Where possible, we based assumptions on information from published clinical data (ie, to estimate the number of pregnancies ending in late miscarriage) and nationally representative survey data (ie, to obtain age-specific fertility rates used in estimating miscarriages). Some information may be challenging for respondents to accurately provide (ie, percent of PAC cases treated at their facility stemming from legal abortion), but the weighted proportion of cases removed for this reason $(5.4 \%)$ was consistent with expectations (ie, between $3 \%$ and $6 \%$ ) based on prior studies. ${ }^{31}{ }^{32}$ We also assumed that
HFS respondents are able to accurately estimate PAC caseloads within the definitions provided (see online supplementary appendix 2), though aspects of this may be challenging, such as excluding women who present with normal bleeding following medication abortion. It is also theoretically possible that some abortions could have been misreported as PAC, if providers (perhaps particularly those in lower-level facilities) felt reluctant to report induced abortions. Future studies in similar mixed-legal settings could further ensure that all legal medication abortions (ie, those in which medications are provided at the health facility, and those for which prescriptions are given by trained, registered healthcare personnel for the patient to procure the medications from a pharmacist or dispensary) are captured in caseload estimates by asking about each provision method separately. AICMs must also assume accuracy of information collected in the KIS (ie, distributions of abortion types by provider type, likelihood of complications and likelihood of accessing treatment for complications, across the four population subgroups, online supplementary appendix 3) used to construct multipliers. This information is based on opinions from knowledgeable informants, and not obtained directly from women undergoing abortion. We carefully selected respondents across all 10 regions who were considered deeply knowledgeable about abortion in Ghana, and censored respondents with the lowest self-reported and interviewer-reported certainty scores. The AICM also assumes that the distribution by wealth and residential status of women having an induced abortion is similar to the distribution of all women in Ghana, though differences in rates of unintended pregnancy, or propensity to abort, may vary by subpopulation. Our sampling and weighting procedures enabled us to convey uncertainty via $95 \%$ CIs around national PAC and abortion caseload estimates, which has not been a feature in all prior AICMs. However, our multipliers were applied to the lower bounds, estimates, and upper bounds of our PAC caseload estimates, so overall $95 \%$ CIs do not take the uncertainty of the multipliers into account.

Safe abortion services have been legal in Ghana for over three decades, so the extent to which Ghanaian women appear to need to resort to procuring illegal abortions is concerning. Our analysis suggested that while $90 \%-100 \%$ of teaching or regional hospitals reported providing safe abortion services, the proportion of lower level facilities that reported the same was much smaller, which may limit individual access to safe and legal abortion services in Ghana. Future analyses will assess additional issues related to abortion, such as examining costs and quality of care for PAC and abortion services, investigating why some facilities do not provide safe abortion, and understanding how the public and healthcare providers perceive abortion legality in Ghana. If individuals perceive abortion services in approved facilities as having inadequate availability or confidentiality, high stigmatisation, poor quality or high cost, or if they are unaware of the conditions under which 
legal abortion may be obtained, this could lead them to resort to informal abortion care, which may be unsafe. In turn, unsafe abortion could have serious consequences for Ghanaian women's health and survival. Ensuring that Ghanaians are supported to prevent unintended pregnancy through affordable, accessible contraceptive services, awareness of the provisions of the current abortion law, and access to safe abortion services and PAC when needed are important components of efforts to reduce maternal mortality in Ghana.

\section{Author affiliations}

${ }^{1}$ Guttmacher Institute, Manhattan, New York, USA

${ }^{2}$ Department of Epidemiology, Johns Hopkins University Bloomberg School of Public Health, Baltimore, Maryland, USA

${ }^{3}$ Department of Population, Family and Reproductive Health, School of Public Health, Kwame Nkrumah University of Science and Technology, Kumasi, Ghana ${ }^{4}$ Department of Epidemiology and Biostatistics, School of Public Health, Kwame Nkrumah University of Science and Technology, Kumasi, Ghana

${ }^{5}$ Department of Obstetrics \& Gynaecology, School of Medicine and Dentistry, Kwame Nkrumah University of Science and Technology, Kumasi, Ghana ${ }^{6}$ Department of Population, Family and Reproductive Health, Johns Hopkins University Bloomberg School of Public Health, Baltimore, Maryland, USA

\section{Twitter Chelsea B Polis @cbpolis}

Acknowledgements We are grateful to our entire fielding team and all study participants. We are also grateful to Jim Lepkowski for assistance developing our sampling and weighting plan, Joe Flack for programming our questionnaires in Open Data Kit, Jesse Philbin for coding assistance and Ayana Douglas-Hall, Marjorie Crowell, Doris Chiu and Ernest Ekutor for research assistance at various stages of the project. This study was made possible by UK Aid from the UK Government and a grant from the Dutch Ministry of Foreign Affairs.

Contributors CBP, EO, SCK, EKN, RL-R and SOB led the conceptualisation of the project. CBP, PWC, EO, SCK, EKN, RL-R and SOB participated in developing aspects of the methodological approach used. CBP, PWC, RH, EKN and SOB participated in programming and implementing computer code for the analysis. CBP and PWC verified the overall reproducibility of research outputs. CBP and PWC conducted the formal analysis, with assistance from RH. E0, EKN and RL-R led the data collection efforts. CBP, PWC, EO, SCK, RH, EKN and SOB provided resources in terms of study materials, contact with respondents, and computing resources. CBP, PWC, RH, EKN and SOB performed data curation to manage and clean data. CBP and PWC wrote the original draft of the manuscript. CBP, PWC, EO, SCK, RH, EKN, RL-R and SOB participated in reviewing and editing the draft. CBP, EO, SCK and SOB had oversight and leadership responsibility for research activity planning and execution, including mentorship external to the core team. CBP, PWC, EO, RH, EKN and SOB were responsible for managing and coordinating research activity planning and execution. CBP and SCK were responsible for acquisition of the funding support for the project, leading to this publication. CBP authored and the entire team reviewed appendices 1, 2 and 3.

Funding This study was made possible by UK Aid from the UK Government and a grant from the Dutch Ministry of Foreign Affairs.

Disclaimer The views expressed are those of the authors and do not necessarily reflect the positions and policies of the donors.

Competing interests None declared.

Patient and public involvement Patients and/or the public were not involved in the design, or conduct, or reporting, or dissemination plans of this research.

Patient consent for publication Not required.

Ethics approval We obtained ethical approval from Guttmacher's Institutional Review Board (IRB), the Johns Hopkins Bloomberg School of Public Health IRB, and the School of Medical Sciences/Komfo Anokye Teaching Hospital Committee on Human Research, Publications and Ethics (CHRPE/AP/210/18). The Ghana Health Service provided administrative clearance for the study.

Provenance and peer review Not commissioned; externally peer reviewed.

Data availability statement Deidentified versions of the raw Health Facilities Survey and Knowledgeable Informants Survey datasets collected by the authors and used in this analysis are available from the Guttmacher Institute upon reasonable request to researchers who wish to use the data for scholarly analysis. To discuss obtaining copies of these datasets, please contact popcenter@ guttmacher.org with the detailed protocol for your proposed study, and information about the funding and resources you have to carry out the study. Data from the Ghana 2017 Maternal and Health Survey are available here: https://dhsprogram. com/what-we-do/survey/survey-display-506.cfm.

Open access This is an open access article distributed in accordance with the Creative Commons Attribution Non Commercial (CC BY-NC 4.0) license, which permits others to distribute, remix, adapt, build upon this work non-commercially, and license their derivative works on different terms, provided the original work is properly cited, appropriate credit is given, any changes made indicated, and the use is non-commercial. See: http://creativecommons.org/licenses/by-nc/4.0/.

\section{ORCID iD}

Chelsea B Polis http://orcid.org/0000-0002-1031-7074

\section{REFERENCES}

1 Morhee R, Morhee E. Overview of the law and availability of abortion services in Ghana. Ghana Med J 2006;40:80-6.

2 Rominski SD, Lori JR. Abortion care in Ghana: a critical review of the literature. Afr J Reprod Health 2014;18:550-35.

3 Ganatra B, Gerdts C, Rossier C, et al. Global, regional, and subregional classification of abortions by safety, 2010-14: estimates from a Bayesian hierarchical model. Lancet 2017;390:2372-81.

4 Ministry of Health of the Republic of Ghana. Prevention \& Management of Unsafe Abortion: Comprehensive Abortion Care Services Standards and Protocols. Accra, Ghana: Ministry of Health, 2012.

5 Aniteye P, O'Brien B, Mayhew SH. Stigmatized by association: challenges for abortion service providers in Ghana. BMC Health Serv Res 2016;16:1-10.

6 Sundaram A, Juarez F, Ahiadeke C, et al. The impact of Ghana's R3M programme on the provision of safe abortions and postabortion care. Health Policy Plan 2015;30:1017-31.

7 Chavkin W, Baffoe P, Awoonor-Williams K. Implementing safe abortion in Ghana: "We must tell our story and tell it well". Int $J$ Gynaecol Obstet 2018;143:25-30.

8 Asamoah BO, Moussa KM, Stafström M, et al. Distribution of causes of maternal mortality among different socio-demographic groups in Ghana; a descriptive study. BMC Public Health 2011;11:1-10.

9 Ghana Statistical Service (GSS), Ghana Health Service (GHS), ICF. Ghana maternal health survey, 2017. Accra, Ghana: GSS, GHS, ICF, 2018. Available: https://www.dhsprogram.com/pubs/pdf/FR340/ FR340.pdf [Accessed 12 Apr 2019].

10 World Health Organization. Trends in maternal mortality: 1990 to 2015: estimates by WHO, UNICEF, UNFPA, World Bank Group and the United nations population division. Geneva: World Health organization, 2015. Available: https://apps.who.int/iris/bitstream/ handle/10665/194254/9789241565141_eng.pdf;jsessionid=94C9 77EF63E846A22746780A48ECC009? sequence $=1$ [Accessed 4 Jun 2019].

11 Lithur NO. Destigmatising abortion: expanding community awareness of abortion as a reproductive health issue in Ghana. Afr $J$ Reprod Health 2004;8:70-4.

12 Aniteye P, Mayhew SH. Shaping legal abortion provision in Ghana: using policy theory to understand provider-related obstacles to policy implementation. Health Res Policy Syst 2013;11:1-14.

13 Awoonor-Williams JK, Baffoe P, Ayivor PK, et al. Prevalence of conscientious objection to legal abortion among clinicians in northern Ghana. Int J Gynaecol Obstet 2018;140:31-6.

14 Adde KS, Darteh EKM, Kumi-Kyereme A, et al. Responsiveness of Health Professionals to Postabortion Care at a Regional Level Hospital in Ghana: A Qualitative Study of Patients' Self-Reports. Int $J$ Reprod Med 2018;2018:1-7.

15 Appiah-Agyekum NN. Medical abortions among university students in Ghana: implications for reproductive health education and management. Int J Womens Health 2018;10:515-22.

16 World Health Organization. Medical management of abortion. Geneva: World Health Organization, 2018.

17 Faúndes A, Santos LC, Carvalho M, et al. Post-abortion complications after interruption of pregnancy with misoprostol. Adv Contracept 1996;12:1-9.

18 Juarez F, Singh S, Garcia SG, et al. Estimates of induced abortion in Mexico: what's changed between 1990 and 2006? Int Fam Plan Perspect 2008;34:158-68. 
19 Miller S, Lehman T, Campbell M, et al. Misoprostol and declining abortion-related morbidity in Santo Domingo, Dominican Republic: a temporal association. BJOG Int J Obstet Gynaecol 2005;112:1291-6.

20 Rossier C. Estimating induced abortion rates: a review. Stud Fam Plann 2003;34:87-102.

21 Jones RK, Kost K. Underreporting of induced and spontaneous abortion in the United States: an analysis of the 2002 national survey of family growth. Stud Fam Plann 2007;38:187-97.

22 Ahiadeke C. Incidence of induced abortion in southern Ghana. Int Fam Plan Perspect 2001;27:96-101.

23 Adjei G, Enuameh Y, Asante KP, et al. Predictors of abortions in rural Ghana: a cross-sectional study. BMC Public Health 2015;15:202.

24 Sedgh G, Bearak J, Singh S, et al. Abortion incidence between 1990 and 2014: global, regional, and subregional levels and trends. Lancet 2016;388:258-67.

25 Personal Communication between Dr. Chelsea Polis, Guttmacher Institute and Dr. Jonathan Bearak, Guttmacher Institute 2019.
26 Keogh SC, Polis CB, Otupiri E, et al. Comparing five approaches to estimating abortion incidence in Ghana. (under review);2019.

27 Singh S, Juarez F, Prada E, et al. Estimating abortion incidence: assessment of a widely used indirect method. Popul Res Policy Rev 2019;38:429-58.

28 Sedgh G, Keogh SC. Novel approaches to estimating abortion incidence. Reprod Health 2019;16:16-44.

29 Personal Communication between Dr. Chelsea Polis, Guttmacher Institute and Dr. Koku Awoonor-Williams, National CHPS coordinator 2018.

30 Boah M, Bordotsiah S, Kuurdong S. Predictors of unsafe induced abortion among women in Ghana. J Pregnancy 2019;2019:9253650.

31 Warriner IK, Wang D, Huong NTM, et al. Can midlevel health-care providers administer early medical abortion as safely and effectively as doctors? a randomised controlled equivalence trial in Nepal. Lancet 2011;377:1155-61.

32 Puri M, Singh S, Sundaram A, et al. Abortion incidence and unintended pregnancy in Nepal. Int Perspect Sex Reprod Health 2016;42:197. 